\title{
Design and Practice of Universal Management System in R ural Digital Communities
}

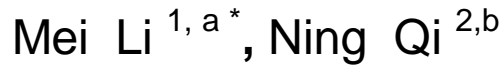 \\ ${ }^{1}$ Department of Architecture, ChangChun Civil Engineering Institute, ChangChun, 130021 \\ ${ }^{2}$ Department of Architecture, ChangChun Civil Engineering Institute, ChangChun, 130021 \\ a76682911@qq.com, ${ }^{b} 592816256 @ q q . c o m$
}

Keywords: Rural digital community; database; integrated services platform of digital community Abstract. Digital services in rural communities is an important part of the rural community construction so that strengthening the construction of rural digital community is significant to accelerate the new rural construction and coordinated development of urban and rural economic. In this paper, through GIS data management and analysis function, to establish spatial and business databases, build integrated service information platform of electronic agricultural services, e-commerce, e-government, design digital community management system to meet the current new management needs of rural communities and provide the access to the system implementation.

\section{Introduction}

Currently, digital technology has become important evaluation criteria in urban and rural competitiveness. Digital management has multiple levels, and community level is the bond connected to government and individual. China is a large agricultural country, the majority of the population and land are concentrated in rural areas. So rural communities are not only the most basic level in the rural administrative system, but also the organizational platform of rural public services and public administration. Therefore, digital construction focused on rural communities as the unit is an important guarantee to realize development strategy of the integration of urban and rural.

\section{Concept and Development Background of Rural Digital Community}

Concept of Rural Digital Community. Rural communities are a new pattern of rural residents during urbanization and new rural construction. New rural communities are formed by a relocation in general, so personnel background is more complicated than the past rural communities. Based on the level of social security, community residents includes rural security (farmers), town security (landless farmers and town enterprise workers) and social security (city residents). Rural communities have features both the traditional "village" and urban areas "community" because of its geographical characteristics (small town) and configuration of community residents (a higher proportion of landless peasants) [1]. Rural digital community is the organically connected community between providers of management and service and each household by digitizing information in a particular area and administrative area. This digital network systems make social information provider, community managers and residents interact in real-time information and in all its forms, also create a colorful virtual community which still has basic properties of communities.

Development Background of Rural Digital Community.Rural community is an important component of the socialist new rural construction. So developing rural community is not only important measure to improve the quality of farmers' life and promote the process of civilization, but also internal needs to build a harmonious society. "CPC Central Committee on rural reform and development of several major issues" pointed out: we must improve the rural social management system, strengthen rural community development and maintain social harmony and stability in rural areas. Construction of a new IT-based rural digital community has great significance to enhance 
efficiency of the community, improve community service and management level and accelerate the construction of a harmonious and stable community.

\section{Construction Target and Conditions of Rural Digital Community}

Construction Target of Rural Digital Community.Under the background of promoting rural modernization by the country, construction of rural digital community aims to make rural area as "modern life community", like prosperous communities, harmonious community, community service, cultural communities, livable communities and vibrant community. Rural area can achieve the transformation of modern management based on the real needs of farmers through the construction of community which is the smallest unit of society.

Infrastructure Construction in Rural Digital Community.As tilting the agricultural policy in the central document, the call of industry nurturing agriculture, agriculture has been Blue Ocean in the next decade after 2010. Till December 2013, the rural netizens reached 177 million, 21.01 million more than last year, an increase of $13.5 \%$. By the end of 2013, rural population in China's internet users accounted for $28.6 \%$, which is the highest proportion in recent years. Rural households owned computer reached 10 units from every hundred in 2010 after the start into the fast lane, also reached 21.4 units in 2012, which was an increase of 3.4 units over the previous year, an increase of $19.2 \%$ [2].The popularity of the internet provides the implementation basis for the construction of rural digital community.

\section{Overall Frame of Rural Digital Community Management System}

Frame of the system is based on database and geographic information and set communications carriers broadband networks, wireless networks and hardware network infrastructure as the transmission channel. Therefore building the application layer on top of the infrastructure layer and setting personal computers and smart Mobile as the terminal can provide the most direct application experience for the digital community managers and end users, build integrated management system through combining the government administration and services, farmer-farm and business needs with the application of modern computer technology and ultimately with standards, integrate with the digital city and realize the community construction model sharing information resources between the government, farmers, businesses and cities.

Establish Comprehensive Information Database of Rural Communities. To establish spatial database and business databases by using GIS powerful data management and analysis abilities. The implementation of spatial database system is to make designed spatial database achieve code, collect data into library space, and build spatial database management information systems [3]. Furthermore, to establish residential geocoding, which can realize three-dimensional household link among resident, residence address and geographical space by house number address code.

Build General Service Platform of Digital Community. Based on GIS technology, spatial database technology, the use of GIS platform software management, the principle of "unity, generic, science, standards, sharing", the integration of a variety of information resources, completing the mesh division for the area, data census of components and event, electronic mapping and data entry, digital community can provide farmers with a comprehensive range of information and services, build a comprehensive service information platform to develop a comprehensive "digital community" platform, and realize the resource digitization of rural community management and community service information. Rural digital community service platform will cover all kinds of business in rural communities. Through the application of digital platforms, rural living and production diversification can be meet by establishing an integrated information service system such as multi-functional community employment, community sanitation, community assistance and security, community education, community sports culture, social welfare and the floating population management, and 
market-oriented service system such as payment services, meteorological, agricultural and agricultural production. Function modules of application platform can be summarized as e-farm, e-commerce, and e-government (see Fig.1).

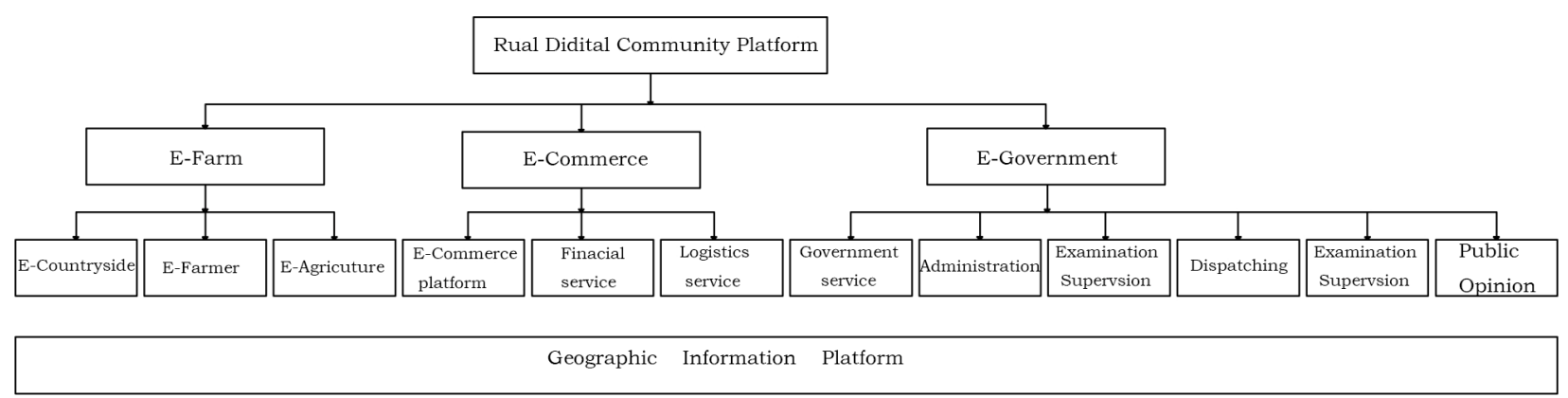

Fig. 1 Function Modules Schematic of Rural Digital Community Integrated Service Platform.

E-farm function includes: firstly, the development of agricultural production applications and product, such as low cost of the development, easy operation and practical hardware products; secondly, building agriculture dynamic monitoring and rapid reporting system, such as monitoring and dispatching the distribution of major agricultural natural disaster, security and quality control of agricultural products, and improving the ability to cope with emergencies and deal with rural market risk [4]; thirdly, building rural information service system, such as taking a variety of service channels and modes, achieving access to diversified, personalized and scientific information, and building an information service platform for service of agriculture, rural areas and farmers; lastly, the construction of agricultural and rural information resources, such as collecting standards, publishing standards, data exchange standards through standardized data, achieving integration and full sharing of resources by the distributed shared way.

E-commerce function includes: firstly, building the agricultural business platform to facilitate the farmers for sale of agricultural products, and to realize the value of agricultural transformation; secondly, promoting farm information link system which provide supply and demand information to conduct online signing and trading pilot; thirdly, strengthening associates and improving logistics to establish modern circulation system of agricultural products and rural consumer business networks by modern logistics and chain management.

E-government function includes: firstly, building subsystems such as the construction of party building, administration, government, green channel, convenience services, web services, calling services, command and control, performance evaluation and platform management; secondly, building village-level digital library network and rural distance training system; thirdly, developing management software and application systems of low-cost "card" online payment systems; lastly, linking the new rural cooperative medical information system to solve difficult problems of medical treatment for farmers.

\section{Access to Rural Digital Community Management System}

The access to rural digital community service system includes six parts which are platform construction, data collection, theoretical research, software development, platform testing, and establishing demonstration communities.

Platform Construction. Platform construction of system application take the internet website as main part. Considering the economic ability of rural communities and management staff shortage, the website is recommended to rent server for the access, or the whole website content will be moved to the next higher authorities of the corresponding channel or column, which can not only save money, but also bring more effective integration with website resources of higher authorities. 
Data Collection. Combined with the specific circumstances of the daily management of rural communities, rural communities comprehensive data are collected and put into library. Meanwhile, existing database resources related departments at all levels can be taken the advantage, and unify with the standard of the unity of the existing database systems to facilitate future data sharing.

Theoretical Research. In the platform construction, involved Platform building technology, spatial database engine technology, address coding technology, image quickly engine technology, emergency risk analysis models need to be researched.

Software Development. The design of software part in integrated services platform can be outsourced to software development company or ask expert to purchase software products directly.

Platform Testing: After program code of each module unit is completed, the platform testing, functional module interfaces testing, data structures testing, and path testing need to be done.

Establishing demonstration communities. After selected demonstration communities as serving platforms, according to the feedback on the platform to make changes and improve, the meaningful "digital community" demonstration can be established.

\section{Summary}

The new rural community is the inevitable product of China's rural modernization development. Establishing new digital rural communities is not only an improvement for the new rural community management, but also a useful practice for the rural modernization. The system establishes spatial database and business databases through a powerful data management and analysis capabilities by GIS, builds integrated service information platform, and makes rural community management and community services information resources digital, so science and technology can be helpful for people truly. Of course, the Rural Digital Community Management System is actually a virtual community, and it must rely on the support of the real community, which is the reflection and extension of real communities. The construction of "Rural Digital Community" in China is still only at the initial stage of exploration, real practice is not too much. With the improvement of "three rural" work and development of rural information technology, especially the promotion of triple network, the new future management systems in rural communities will achieve more breakthroughs in technology, and play a greater role in the function.

\section{Acknowledgements}

The project was financially supported by the research project of Science and Technology Department of Jilin province (20140418018FG).

\section{References}

[1]. Jianlin Chen, Jingyin Zhao. Thought on Construction Pattern of Rural Community Informatization[J]. Agriculture Network Information, in Chinese 2009 (12): 43.

[2]. Hong Zhang. China Digital Divide report 2013. http://www.sic.gov.cn/News/287/2782.htm,2014.

[3]. Xincai Wu. WebGIS based on Flex development [M]. Beijing: Electronic Industry Press . in Chinese 2011: 210-218.

[4]. Xian yang Qin, Chunjiang Zhao, Baozhu Yang. Main fields of research and application for information technology in new countryside [J]. Agriculture Network Information, in Chinese 2006 (12): 7. 